\title{
A Novel Design of Fuzzy Controlled D-STATCOM with Reduced DC Link Voltage
}

\author{
Mr.Mallavolu.MalleswaraRao \\ Assistant Professor, EEE Department \\ RISE Krishna Sai Prakasam Group of \\ Institutions, Ongole, Near valluru, A.P
}

\author{
Mr.G.Ramesh \\ Assistant Professor in EEE Department \\ Bhimavarm Institute of Engineering \& \\ Technology Pennada, Bhimavarm, A.P.
}

\begin{abstract}
Proposed Controller with control algorithms are used for load compensation and voltage regulation in D-STATCOM. Because of variation in DC Capacitor Excitation voltage, load changes might affect the Compensation Procedure. In this paper, a fuzzy logic based integration method is proposed to improve the transient performance of the dc link voltage. Proportional and integral gains of the PI controller vary the transient period time immediately after the load variation. PI gains using expert knowledge of system behavior and higher sampling during the transient period improves the performance of the controller. Error in dc link reduces capacitor voltage during load change compared to normal PI controller. Efficiency and settling time of voltage is also fast, will be proved using this proposed approach with MATLAB simulation results.
\end{abstract}

Keywords: DC link voltage control, D-STATCOM, Fuzzy supervisor, PI controller, transient response, VSI.

\section{INTRODUCTION}

Electric power quality may be defined as a measure of how well electric power service can be utilized by customers. Power Quality problem is an occurrence manifested as a nonstandard voltage, current or frequency that results in a failure or a mis-operation of end user equipment. To compensate harmonics conventional Passive Filters are used for specific number of harmonics. To compress total harmonic content Active Power Filters are used. For all types of power quality solutions at the distribution system voltage level D-FACTS also called as Custom Power Devices are introduced to improve Power Quality.

There are many solutions in mitigating the power quality problems at a distribution system such as using surge arresters, active power filters, isolation transformer, uninterruptible power supply and static VAR compensator. It proposed a new D-STATCOM control algorithm to compensate Sags.LCL filter is introduced to reduce THD value.

The simulation results show that the voltage sags can be mitigate by inserting D-STATCOM to the distribution system. By adding LCL Passive filter to D-STATCOM, the THD reduced very effectively. Thus, it can be concluded that by adding D-STATCOM with LCL filter the power quality is improved. It is observed from these studies that the proposed D-STATCOM with LCL filter gives better improvement in Power Quality.

With the increasing application of nonlinear loads, the appearance of power quality problems is inevitable. In recent years, the rapidly increasing use of nonlinear power-electronics devices (e.g. thyristor, diode, adjustable speed drives (ASD), programmable-logic controllers) has brought many power-quality (PQ) problems. Therefore, a novel device named Distribution Static Compensator (DSTATCOM) a shunt APF through a common DC-link capacitor is proposed. Where the main function of the shunt APF is compensating the current distortion generated by nonlinear load, correcting power factor and regulating the DC-link voltage from the distribution system. In this Project Novel Filter based D-STATCOM is developed.

\section{Praposed Topology}

Proposed control algorithm aims to provide fast voltage regulation at the load terminal during voltage disturbances while retaining the advantages of CCM during normal operation. Firstly, currents that must be drawn from the source to get advantages of CCM are computed. Using these currents, 
magnitude of voltages that need to be maintained at load terminal is computed. If this voltage magnitude lies within a permissible range then same voltage is used as reference voltage to provide advantages of CCM. If voltage lies outside the permissible range, it is a sign of voltage disturbance and a fixed voltage magnitude is selected as reference voltage. A two loop controller, whose output is load angle, is used to extract load power and VSI losses from the source. Finally, a discrete model is derived to obtain switching pulses. All these steps are presented in detail in this section.

During normal operation, load voltage must be regulated in such a way that following advantages provided by CCM operation are achieved:

1. Source currents are balanced and sinusoidal.

2. Unity power factor (UPF) at PCC.

3. Source supply load average power and VSI losses.

To achieve all aforementioned objectives, instantaneous symmetrical component theory [15] is used to get reference source currents. D-STATCOM makes the load voltages balanced and sinusoidal, but still may contain some switching harmonics which will give unacceptable reference source currents when directly used. Therefore, positive sequence component of load voltages are extracted and used to compute reference source currents are calculated.

\subsection{Proposed D-Statcom Topology for Pq Improvement Features by Using Pi Controller}

Proposed Novel Multifunctional Distributed Compensation Scheme can mitigate several power quality (PQ) problems. In current control mode (CCM), it injects harmonic and reactive components of load currents to make source currents balanced, sinusoidal, and in phase with load voltages. In voltage control mode (VCM), it regulates load voltage at a constant value to protect sensitive loads from voltage disturbances such as sags, swells, transients, and/or fluctuations. However, the objectives of these two modes are different and it can be

Achieve by proposed D-STATCOM. Fig.7.2 gives the Simulation model of system with M-DSTATCOM. In a distribution system with a non-linear load connected to the system will generates harmonics. A nonlinear load in a power system is characterized by the introduction of a switching action and consequently current interruptions. This behavior provides current with different components that are multiples of the fundamental frequency of the system. These components are called harmonics. The amplitude and phase angle of a harmonic is dependent on the circuit and on the load it drives.

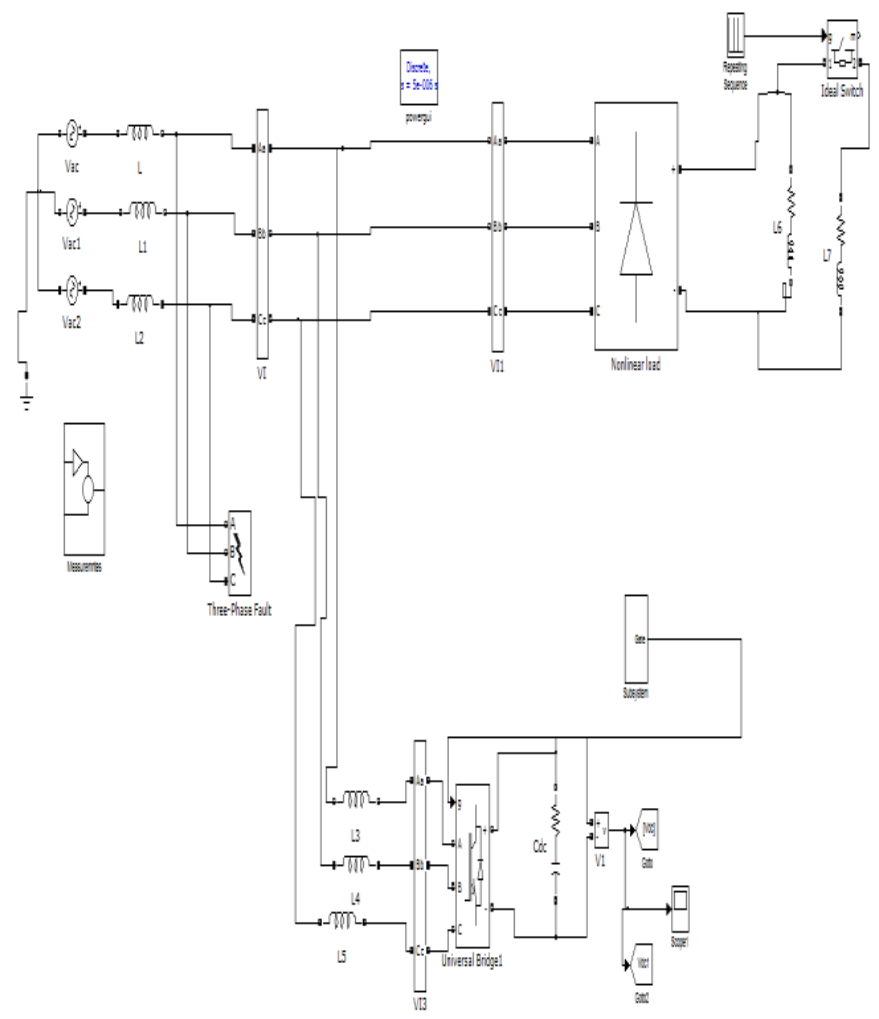

Fig1. Matlab/Simulink Model of Proposed D-STATCOM Topology for PQ Improvement Features. 


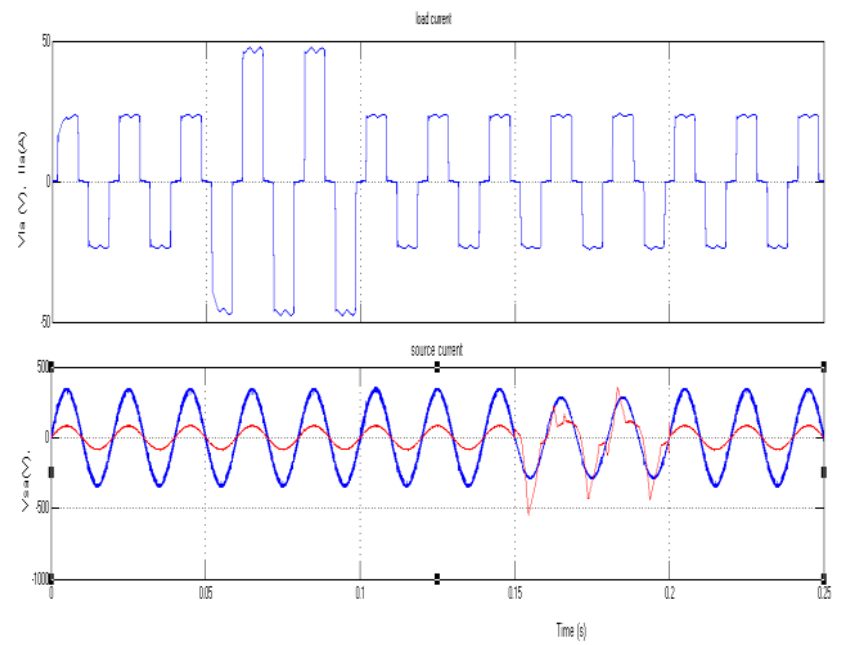

Fig2. Phase-a wave forms before, during, and after load change.(a) Load current. (b) Source voltage and source current of

\subsection{Proposed D-Statcom Topology with Stiff Source}

Initially, a three phases and non-linear load is connected. For achieved multifunctional D-STATCOM operation there phase fault is connected at source side. And at load side an ideal switch breaker is connected. Which is closed at $\mathrm{t}=0.05 \mathrm{~s}$. Then load is increased but source currents are balanced and sinusoidal and CCM mode is achieved. It can be seen that both voltage and currents are in phase with each other, maintain unity power factor. Increased load current will not effect on source performance and vice versa. It showed in phase-a, is shown in fig. 2 .

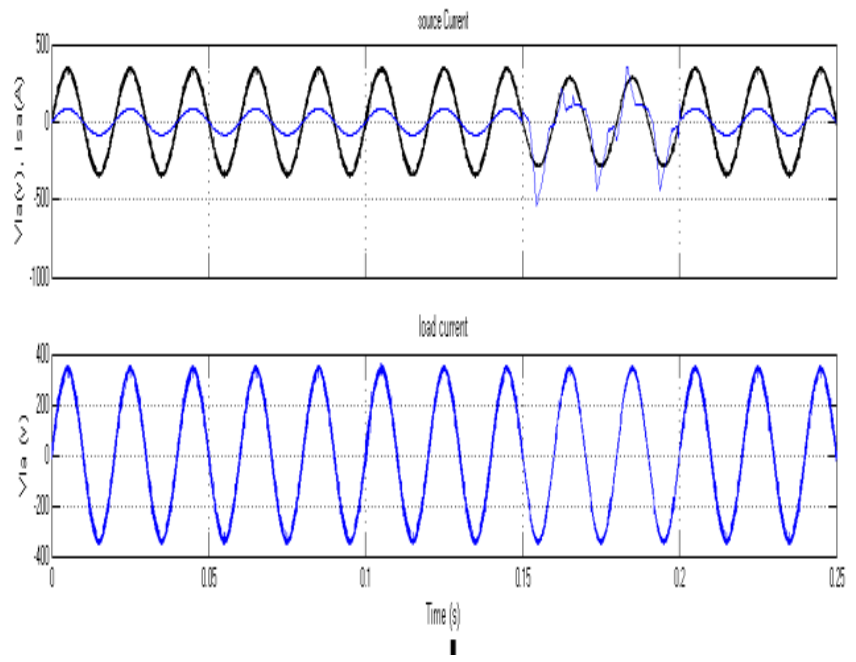

Fig3. Phase-a: waveforms before, during, and after sag.(a) Source voltage and source current. (b) Load voltage of Proposed D-STATCOM Topology with stiff source.

At $\mathrm{t}=0.15 \mathrm{~s}$, fault is created by three phase fault at source side. But a fast voltage regulation is provided at load side. It can be seen in fig.3, here voltage control mode is performed.

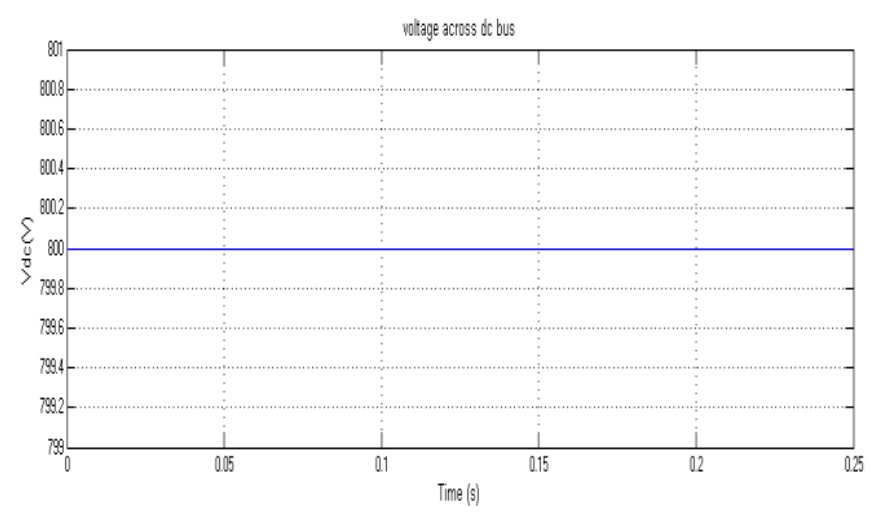

Fig4. Voltage across dc bus 


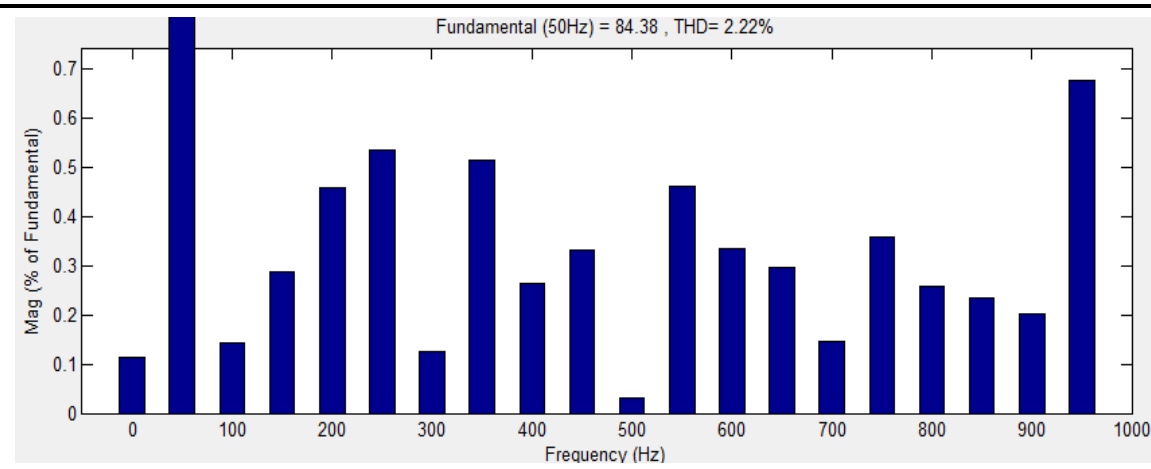

Fig5. FFT analysis for source current

Fig.4 shows the load angle shows the voltage at dc bus which is regulated around $800 \mathrm{~V}$ during entire operation. Fig.5 shows FFT analysis for source current.

\subsection{Proposed Fuzzy Logic Controller}

L. A. Zadeh presented the first paper on fuzzy set theory in 1965. Since then, a new language was developed to describe the fuzzy properties of reality, which are very difficult and sometime even impossible to be described using conventional methods. Fuzzy set theory has been widely used in the control area with some application to power system [5]. A simple fuzzy logic control is built up by a group of rules based on the human knowledge of system behavior. Matlab/Simulink simulation model is built to study the dynamic behavior of converter. Furthermore, design of fuzzy logic controller can provide desirable both small signal and large signal dynamic performance at same time, which is not possible with linear control technique. Thus, fuzzy logic controller has been potential ability to improve the robustness of compensator.

The basic scheme of a fuzzy logic controller is shown in Fig.3 and consists of four principal components such as: a fuzzyfication interface, which converts input data into suitable linguistic values; a knowledge base, which consists of a data base with the necessary linguistic definitions and the control rule set; a decision-making logic which, simulating a human decision process, infer the fuzzy control action from the knowledge of the control rules and linguistic variable definitions; a defuzzification interface which yields non fuzzy control action from an inferred fuzzy control action

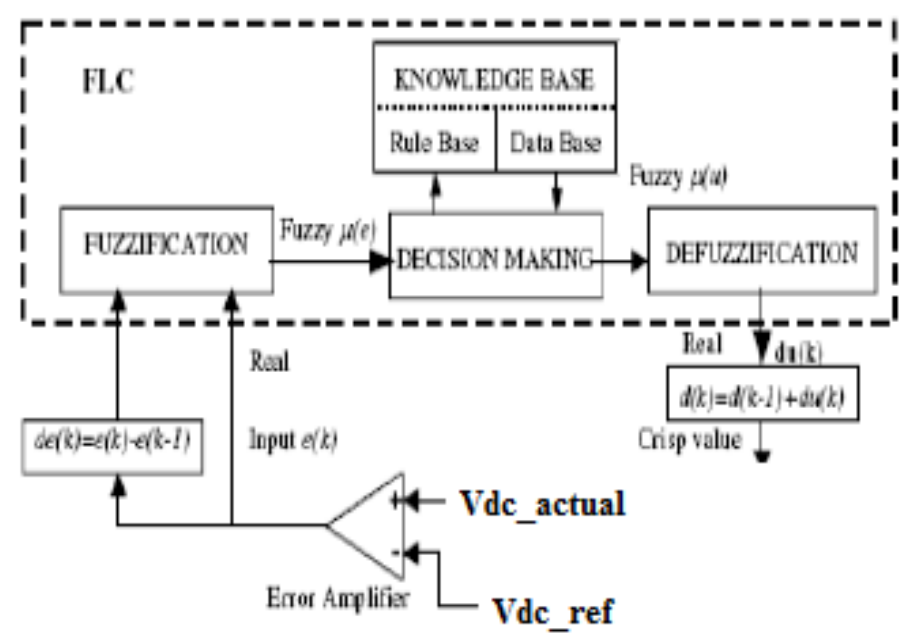

Fig6. Block diagram of the Fuzzy Logic Controller (FLC)

\subsection{Case 2: Praposed D-STATCOM Topology For PQ Improvement Feactures By Using Fuzzy Controller}

Proposed Novel Multifunctional Distributed Compensation Scheme can mitigate several power quality (PQ) problems. In current control mode (CCM), it injects harmonic and reactive components of load currents to make source currents balanced, sinusoidal, and in phase with load voltages. In voltage control mode (VCM), it regulates load voltage at a constant value to protect sensitive loads from voltage disturbances such as sags, swells, transients, and/or fluctuations. However, the objectives of these two modes are different and it can be 


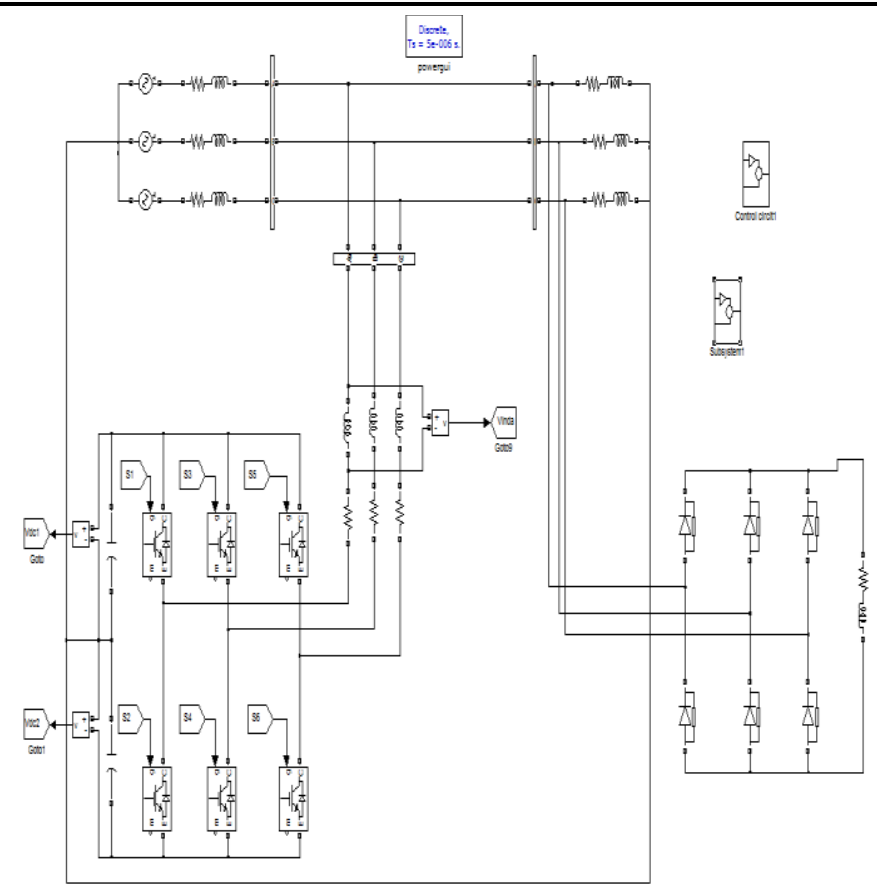

Fig7. Matlab/Simulink Model of fuzzy controlled Topology for PQ Improvement Features.

Achieve by proposed D-STATCOM. Fig.7 gives the Simulation model of system with M-DSTATCOM. In a distribution system with a non-linear load connected to the system will generates harmonics. A nonlinear load in a power system is characterized by the introduction of a switching action and consequently current interruptions. This behavior provides current with different components that are multiples of the fundamental frequency of the system. These components are called harmonics. The amplitude and phase angle of a harmonic is dependent on the circuit and on the load it drives.

In This above table has presented a novel control of an existing UPQC within the source side. In the shunt controller (i) with PI controller and (ii)Fuzzy logic controller to improve the quality of power at PCC for a 3-phase 4-wire UPQC system. By using PI controller we get THD value is $2.22 \%$, but using the Fuzzy logic controller THD value is $0.21 \%$. and The simulation results show that the performance of converter system has been found to be satisfactory for improving the power quality at the consumer premises.

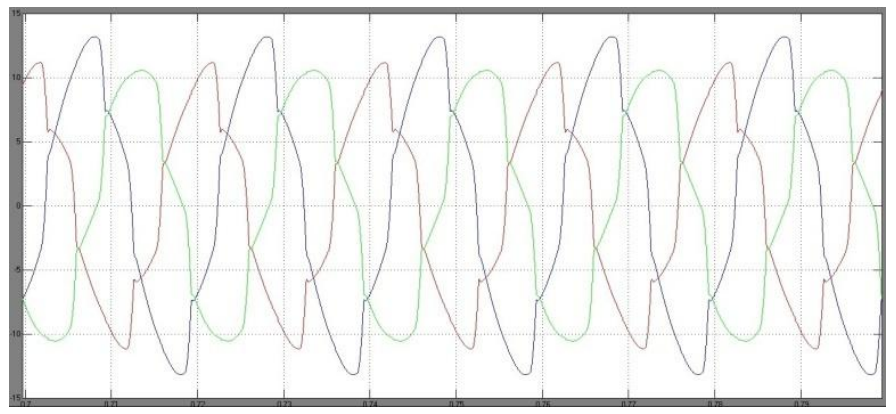

Fig8. simulation result of current and voltage wave forms out phase

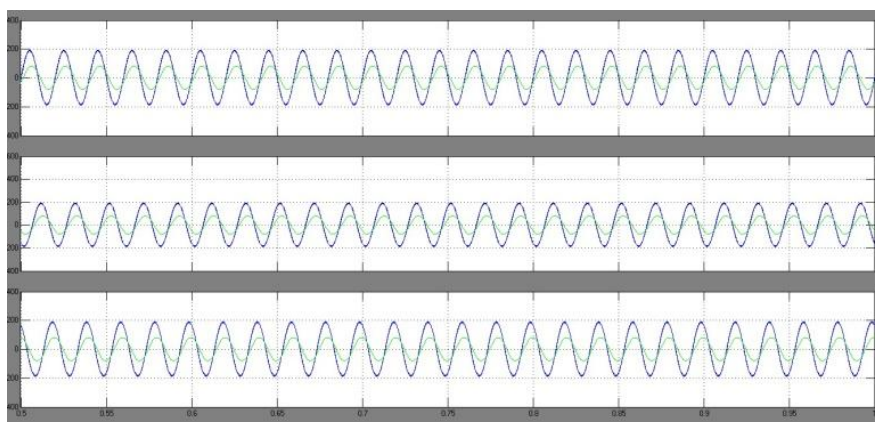

Fig9. Simulation result of current and voltage wave forms in phase 


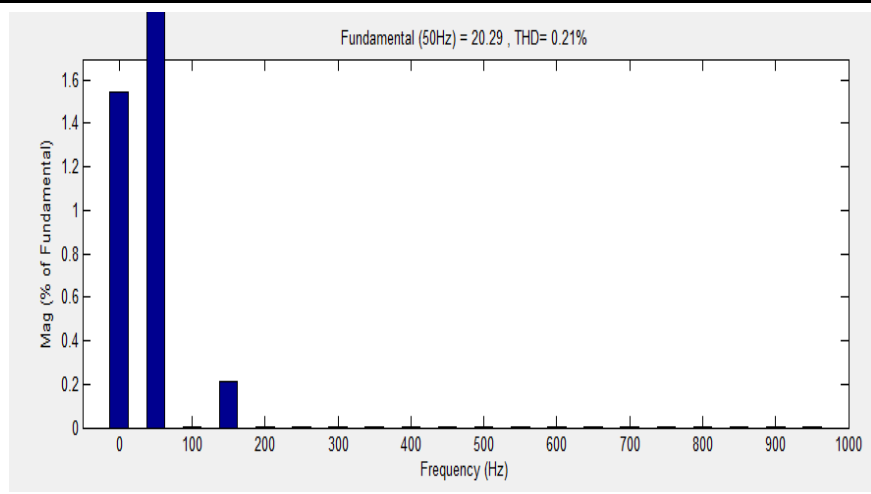

Fig10. FFT analysis for source current

Fig. 8 shows Phase-a wave forms before, during, and after load change. Fig.9 shows Phase-a: waveforms before, during, and after sag. Fig.10 shows FFT analysis for source current.

\section{CONCLUSION}

In this paper D-STATCOM based fuzzy logic controller to the dc link PI controller has been proposed in this paper. System performance can be improves by the supervisor, varies the gain of the PI controller during the transient period. The system has been modeled and simulated in the MATLAB. The performance of the dc link and compensation were observed with and without the fuzzy supervisor. Simulation results show a 50\% reduction in voltage deviation of the dc link voltage with faster settling time. Instantaneous symmetrical component theory has been used for load compensation. Good compensation has been observed as source current THDs is $0.21 \%$ compared to PI controller THD is $2.22 \%$. Thus, through simulation studies, the implementation of a fuzzy supervisor for DC link voltage control in a DSTATCOM using instantaneous symmetrical component theory for load were observed.

\section{REFERENCES}

[1] Chandana kumar and Mahesh K.Mishra "A Multifunctional DSTATCOM Operating under Stiff Source," IEEE Transction on Industrial Electronics, VOL.61, NO.7, July 2014.

[2] 1Noramin Ismail, 2 Wan Norainin Wan Abdullah," Enhancement of Power Quality in Distribution System Using D-STATCOM" The 4th International Power Engineering and Optimization Conference (PEOCO2010), Shah Alam, Selangor, MALAYSIA. 23- 24 June 2010.

[3] H. Akagi, "New trends in active filters for power conditioning," IEEE Trans. Ind. Appl., vol. 32, no. 6, pp. 1312-1322, Nov./Dec. 1996.

[4] A. Nasiri and A. Emadi, "Different topologies for single-phase unified power quality conditioners," in Proc. Conf. Rec. 38th IAS Annu. Meeting Industry Applications Conf., Oct. 12-16, 2003, vol. 2, pp. 976-981.

[5] J. M. Correa, S. Chakraborty,M. G. Simoes, and F. A. Farret, "A single phase high frequency ac microgrid with an unified power quality conditioner," in Proc. Conf. Rec. 38th IAS Annu. Meeting Industry Applications Conf., Oct. 12-16, 2003, vol. 2, pp. 956-962.

[6] B. Han, B. Bae, H. Kim, and S. Baek, "Combined operation of unified power quality conditioner with distributed generation,” IEEE Trans. Power Del., vol. 21, no. 1, pp. 330-338, Jan. 2006.

[7] V. Khadkikar, A. Chandra, 0. Barry and T. D. Nguyen., "Conceptual Study of Unified Power Quality Conditioner (UPQC)"in IEEE ISIE 2006, July 9-12, 2006,pp 1088-1093.

[8] G. W. Chang, "A new approach for optimal shunt active power filter control considering alternative performance indices," IEEE Trans. Power Del., vol. 21, no. 1, pp. 406-413, Jan. 2006.

[9] T. C. Green and J. H. Marks, "Control techniques for active power filters," Proc. Inst. Elect. Eng., Elect. Power Appl., vol. 152, no. 2, pp. 369-381, Mar. 4, 2005.

[10] H.Komurcugil and O.Kukrer, "A newcontrol strategy for single-phase shunt active power filters using a lyapunov function,” IEEE Trans. Ind. Electron., vol. 53, no. 1, pp. 305-312, Feb. 2006.

[11] H. Y. Kanaan, K. Al-Haddad, A. A. Assi, J. B. Sleiman, M. Aoun, and C. Asmar, "Averaged modeling and control of a three-phase series active power filter for voltage harmonic compensation," in Proc. IEEE 29th Annu. Conf. Industrial Electronics Soc., Nov. 2-6, 2003, vol. 1, pp. 255-260. 
[12] M. Vilathgamuwa, Y. H. Zhang, and S. S. Choi, "Modelling, analysis and control of unified power quality conditioner," in Proc. 8th Int. Conf. Harmonics Quality Power, Oct. 14-16, 1998, vol. 2, pp. 1035-1040.

[13] A. K. Jindal, A. Ghosh, and A. Joshi, "Interline unified power quality conditioner," IEEE Trans. Power Del., vol. 22, no. 1, pp. 364-372, Jan. 2007. [14] A. Ghosh and A. G. Ledwich, "A unified power quality conditioner (upqc) for simultaneous voltage and current compensation," Electr. Power. Syst. Res., vol. 59, pp. 55-63, 2001.

[14] K. Mahabir, G. Verghese, J. Thottuvelil, and A. Heyman, "Linear averaged and sampled data models for large signal control of high power factor ac-dc converters," in Proc. IEEE 21st Annu. Power Electronics Specialists Conf. Rec., June 11-14, 1990, pp. 372-381.

[15] Z. Hu, B. Zhang, and W. hua Deng, "Output controllability of switched power converters as switched linear systems," in Proc. 4th Int. Power Electronics Motion Control Conf., Aug. 14-16, 2004, vol. 3, pp. 1665-1668. [17] J. Liu, J. Yang, and Z. Wang, "A new approach for singlephase harmonic current detecting and its application in a hybrid active power filter," in Proc. 25th Annu. Conf. IEEE Industrial Electronics Soc., Nov.29-3 Dec. 1999, vol. 2, pp. 849-854. 